\title{
INFLUENCE OF UV RADIATION ON DIELECTRIC ABSORPTION AND DIELECTRIC STRENGTH OF HALLOYSITE NANOTUBES FILLED POLYETHYLENE COMPOSITES
}

\author{
Petr KADLEC ${ }^{*}$, Radek POLANSKÝ ${ }^{* *}$ \\ *Department of Technologies and Measurement, Faculty of Electrical Engineering, \\ University of West Bohemia, Univerzitní 8, 30614 Pilsen, Czech Republic, e-mail: kadlecp6@ket.zcu.cz \\ ${ }^{* *}$ Regional Innovation Centre for Electrical Engineering, Faculty of Electrical Engineering, \\ University of West Bohemia, Univerzitní 8, 30614 Pilsen, Czech Republic, e-mail: rpolansk@ket.zcu.cz
}

\begin{abstract}
This paper deals with the evaluation of the amount of filler influence and the ultraviolet (UV) radiation influence on selected dielectric properties of the innovative type of composites. These composites consist of a linear low-density polyethylene matrix and a clay filler (with different filling levels) that contains halloysite nanotubes (HNT) primarily. The intended application of tested composites in the field of electrical engineering is in insulating systems of power cables. Attention is paid to the analysis of the behaviour of composites in their charging, which is caused by the connection with the direct voltage source. The volume resistivity and polarization indexes are determined based on this analysis. Analysis of charging based on the measurement of the current, which flows through the sample under constant applied voltage, is supplemented with the short evaluation of the material behaviour after the disconnecting of the voltage source and after the electrode shorting when the material is discharged. Furthermore, the measurement of dielectric strength under an alternating electric field as another key parameter of electrical insulating materials is determined. Results of analyses of absorption and resorption processes and the dielectric strength measurement of materials in the delivered state prove a significant effect of the filler percentage in the composite. Subsequently, markedly different values of selected parameters because of material exposure to UV radiation are also determined. Observed changes in dielectric properties caused by UV irradiation are supported by the analysis of the chemical structure of materials via Fourier transform infrared spectroscopy.
\end{abstract}

Keywords: Composite, Dielectric absorption, Dielectric strength, Halloysite nanotubes, Infrared spectroscopy, Polyethylene, Volume resistivity, Ultraviolet radiation

\section{INTRODUCTION}

Each industry branch undergoes fast development at the present time because of dynamic research and implementation of new technologies, processes, materials, etc. The same situation is in the cable industry, which is engaged markedly in a production for power engineering (including cables for renewable energy sources). The research and development of new materials and their shaping and combining is the key issue in the case of innovation of cable production. The design of electrically conductive parts of cables has not changed so much for many years. Improvements that are more notable are occurring, e.g., in the case of optimizing of the electric field configuration thanks to the usage of semiconducting layers into high voltage cables, but the most significant progress is made mainly in the field of electrical insulating materials. The introduction of the part of research on the innovative insulating material is the topic of this contribution.

Electrical insulating materials are currently more and more polymer composites as materials composed of the polymer matrix and additives which improve mechanical and dielectric properties, increase the heat resistance, or influence other properties tested at one time shortly after producing (materials in the delivered state). The great comprehensive improvement of material properties in the delivered state by the addition of additives is of course required, but at least coessential is the continuous monitoring of the influence of additives on the material properties in a certain time interval and under certain external influences. These external influences, which may represent operating conditions of some electrical equipment, may be referred to as degradation factors if they negatively affect material properties and their action leads to a reduction in lifetime of materials. There are many degradation factors whereas in the case of polymer materials used in conventional electrical insulating systems is mainly considered effects of the electric field, elevated temperature and weather conditions (e.g., sunlight with UV component, humidity, and frost).

\section{ISSUE OF SUITABLE MATERIALS FOR DURABLE CABLE INSULATION}

The durable materials suitable for insulating systems of modern cables may be already mentioned polymer composites which represent materials with improved at least some important properties in comparison to the pure polymer (homopolymer, copolymer or polymer blend). It also important that the production of these composites and used additives are as environmentally friendly as possible. Innovative composites exhibit ideally also lower health risks during degradation, especially during combustion.

\subsection{Increasing of cable insulation durability in brief}

A very important issue in this context is the increasing of fire resistance of polymeric materials. Requirements for fire safety are still increased, especially for skyscrapers, shopping centres, metro or other places with a high concentration of people, which is hardly accessible in case of fire or other accidents, and also in power plants. These requirements are met thanks to the application of special types of cables often referred to as Low Fire Hazard Cables (LFHC) or cables based on Halogen Free Flame Retardant (HFFR). The effective flame retardation or at least a combustion inhibition and a minimized formation of 
hazardous combustion products (gases) may be ensured by several ways according, e.g., $[1,2]$.

One possibility of the realization of cable with enhanced flame retardancy is the use of innovative polymer composites consisting of commonly used polymer and small amounts of clay filler for extrusion of basic insulating layers (conductor insulation and cable sheathing). The small amount of filler, in the order of several weight percent, should allow the use of this composite type for cable sheathing as well as for the conductor insulation in which the minimization of larger inhomogeneities is essential due to the interaction of the material with an electric field. The advanced filler which can positively influence the flame retardancy of conventional polymers (e.g., polyolefins), even if only a few weight percent of well-dispersed filler is used, is halloysite in a tubular form (halloysite nanotubes) [3].

In addition to the influence of the thermal field (including the extreme case of combustion in connection with the fire retardancy), the solving of a interaction with electric field in the case of application of the composite polyethylene/HNT as a conductor insulation and the solving of effects of weather in the case of application of the composite polyethylene/HNT as a cable sheathing are important. The influence of the electric field on composites with clay filler may be described, e.g., according to $[4,5]$ and the effects of weather, especially the UV component of sunlight, has already been mentioned, e.g., in [6]. In particular, the effect of UV radiation on dielectric properties of the polyethylene/HNT composite still does not explore so much and therefore this topic is discussed here.

\subsection{Interaction of polymer composites with UV radiation}

The UV radiation, which is generally defined in the range of wavelengths from $200 \mathrm{~nm}$ to $400 \mathrm{~nm} \mathrm{[7],}$ represents a part of the electromagnetic spectrum with significant degradation effects on polymer materials. These effects are originated due to the fact that the UV radiation is characterized by the energy level which is similar to the level of dissociation energies of main bonds of the structure of the polymer. The UV radiation with wavelengths longer than about $280 \mathrm{~nm}$ in the case of real weather with a sunlight [8] can be considered as the factor accelerating the radical chain reaction (autooxidation) [9] which always occurs in polymers placed in the air (oxidizing atmosphere). The acceleration of autooxidation is caused by the formation of radicals as a result of a scission of polymer bonds. The reaction caused primarily by the effects of the oxidizing atmosphere and the UV radiation is called a photo-oxidation which is already described in detail for conventional polymers, e.g., the general description in [10] and the description for polyethylene $(\mathrm{PE})$ in $[8,11]$. However, the reaction course becomes considerably complicated due to the addition of additives that also include the clay filler mentioned in this contribution. The influence of the addition of clay filler on the process of oxidation of PE is described, e.g., in [12].

\subsection{Description of tested materials}

Three chemically different materials were selected for the experiment. Two materials are composites comprising the linear low-density polyethylene matrix and the certain amount of clay filler with the trade name Dragonite HP. Composites contain three and seven weight percent of the filler (henceforth referred to as PE/3HNT and PE/7HNT). The third material is the pure polyethylene tested as the reference material (henceforth referred to as PE). Filler modifications or other additives are not used intentionally to get an idea of the essential influence of filler on a polymer base. Tested materials were extruded into foils with the thickness of $0.30 \pm 0.05 \mathrm{~mm}$ and the length of several meters. Subsequently, square-shaped specimens were cut out of foils for purposes of the absorption analysis and dielectric strength measurement.

The used linear low-density polyethylene was produced as a copolymer of ethylene with 1-hexene and is characterized by a density of $926 \mathrm{~kg} / \mathrm{m}^{3}$ and a melt flow index of $3.3 \mathrm{~g} / 10 \mathrm{~min}$ (at $190{ }^{\circ} \mathrm{C}$ and $2.16 \mathrm{~kg}$ load). The used filler Dragonite HP is mined by Applied Minerals in the USA and consists primarily of halloysite nanotubes. Therefore, this filler is referred to as HNT. Fundamental HNT units are nanotubes formed as a helically arranged aluminosilicate layer with an interlayer space with a potential occurrence of water molecules. The chemical formula of the $\mathrm{HNT}$ is $\mathrm{Al}_{2} \mathrm{Si}_{2} \mathrm{O}_{5}(\mathrm{OH})_{4} \cdot \mathrm{nH}_{2} \mathrm{O}$ [13].

\section{TECHNICAL BACKGROUND OF PERFORMED EXPERIMENT}

Firstly, a procedure for the defined exposure of tested specimens to UV radiation was proposed in the course of the experiment. It was necessary to choose the optimal source of UV radiation representing the most dangerous component of sunlight considering the polymer materials degradation. Subsequently, it was important to design the method of the dielectric absorption analysis and choose the suitable measurement of electrical strength based on valid standards and with available equipment. The last part of the experiment preparation is related to the choice of the optimal method of direct detection of changes in the chemical structure of materials when finally the Fourier transform infrared spectroscopy (FTIR) was selected.

\subsection{Procedure of specimens exposure to UV radiation}

The UV irradiation of specimens was performed by the UV radiation source containing three fluorescent tubular lamps (TL20W/12 RS SLV/25, Philips) placed in one plane. Tubular lamps generate the UV radiation primarily in the range of wavelengths from $290 \mathrm{~nm}$ to $320 \mathrm{~nm}$ with the maximum of spectral power at $302 \mathrm{~nm}$. Specimens were placed in the plane parallel to the plane of fixed tubular lamps at the distance of less than $10 \mathrm{~cm}$. The UV irradiation of three groups of specimens (required for subsequent analysis and measurement) for each tested material was performed. The first group of specimens was irradiated for time period $t_{U V}$ lasting for $50 \mathrm{~h}$, the next group of specimens 
was exposed to UV radiation for $100 \mathrm{~h}$, and the third group of specimens was irradiated for a period of $150 \mathrm{~h}$. The irradiation of tested specimens was performed without interruption for all time periods.

\subsection{Realization of dielectric absorption analysis}

The dielectric absorption analysis was performed on the basis of the measurement of a total (charging) current flowing through the specimen which is placed between measuring electrodes. The used measurement method is referred to as the voltage-current method of the volume resistivity determination and this method was applied according to the standard [14]. Square-shaped specimens with the edge length of $10 \mathrm{~cm}$ (in the case of all tested materials) were measured via an interconnected system of the electrometer Keithley 6517A, the resistivity test fixture Keithley 8009 and a computer with a data logger. The total measuring time, when the test voltage of $1000 \mathrm{~V}$ was applied to the specimen, was 100 minutes. The current flowing through the specimen was recorded every second during the whole measurement and the measurement was repeated three times for each material and each level of UV irradiation (always on a new specimen).

Time dependencies of $i_{c h}\left(t_{c h}\right)$ measured for each material were used for the nonlinear regression analysis whose result is the obtaining of regression curves of all time dependencies. The regression analysis assumes purely exponential function as a mathematical description of the decreasing trend of the total current in the course of the material charging. The calculation of the volume resistivity $\rho_{V}\left(t_{c h}\right)(\Omega \cdot \mathrm{cm})$ at the certain charging time $t_{c h}(\mathrm{~min})$ was made according to equation (1):

$\rho_{V}\left(t_{c h}\right)=\frac{A}{d} \cdot \frac{U}{i_{c h(r)}\left(t_{c h}\right)}$

where $A\left(\mathrm{~cm}^{2}\right)$ is the effective area of the electrode $\left(22.9 \mathrm{~cm}^{2}\right.$ for the used electrode system), $d(\mathrm{~cm})$ is the thickness of the specimen, $U(\mathrm{~V})$ is the test voltage and $i_{c h(r)}\left(t_{c h}\right)$ (A) represents the total charging current (obtained by the regression analysis) at the certain time $t_{c h}$. The final volume resistivity $\rho_{V}$ for the charging current, which may be considered a steady state, was determined for $t_{c h}$ of 100 minutes and for each material.

Polarization indexes $P I_{1}$ and $P I_{10}$ were determined as other important material parameters according to the standard [15]. The polarization index $P I_{I}$ is the ratio of total charging current in the fifteenth and the sixtieth second of the measurement and the polarization index $P I_{10}$ is the ratio of total currents recorded at the end of the first minute and at the end of the tenth minute after application of the test voltage.

The supplementation of the dielectric absorption analysis was carried out on the basis of rapid measurement of the material discharging after the voltage disconnecting and the electrode shorting. The (total) discharging current $i_{r}\left(t_{r}\right)(\mathrm{A})$ recorded at the certain time of discharging $t_{r}(\mathrm{~s})$ was measured for a time period of $300 \mathrm{~s}$. Observed trend of the discharging current corresponding to resorption processes can be clearly visualized and further evaluated via reduced resorption curves. These curves are after transformations (2) and (3):

$$
\begin{aligned}
& x=\ln \left(t_{r}\right)-\ln (15) \text { and } \\
& y=\ln \left|i_{r}\left(t_{r}\right)\right|-\ln \left|i_{r}(15)\right|
\end{aligned}
$$

of measured values of $i_{r}\left(t_{r}\right)$ according to [16] displayed in the first quadrant of the coordinate system. The $i_{r}(15)$ represents the value of the discharging current at the time of $15 \mathrm{~s}$ after the measurement of discharging beginning. The reduced resorption curves character may be described very accurate thanks to the linear regression. Acquired regression lines are described by values of the slope and the coefficient of determination $R^{2}$. The evaluation of reduced resorption curves is performed in this contribution only to determine the effect of UV radiation on the behaviour of the composite with $7 \%$ filling level. Differences in resorption curves for delivered state and for state after the UV irradiation are the most significant for this material.

\subsection{Measurement of dielectric strength}

The dielectric strength $E_{p}(\mathrm{kV} / \mathrm{mm})$, the ratio of breakdown voltage and specimen thickness, of tested materials was determined in the oil under the alternating voltage with the frequency of $50 \mathrm{~Hz}$. The measurement was carried out as a short-time test with the linear voltage increase from the zero to the breakdown voltage approximately of $1 \mathrm{kV} / \mathrm{s}$ and based on the standard [17]. Measured specimens were placed between two identical cylindrical electrodes with a diameter of $25 \mathrm{~mm}$ and with rounded edges. Fifteen electrical breakdowns were performed for each material. Subsequently, average values and standard deviations of $E_{p}$ were calculated.

\subsection{Fourier transform infrared spectroscopy}

The Fourier transform infrared spectroscopy is a less known diagnostic technique in the field of electrical engineering, and it is, therefore, appropriate to mention briefly the function principle. This spectroscopy allows the identification of chemical bonds (bonded atoms and molecules) on the basis of molecular vibrations. These vibrations are characterized by certain parameters (mainly by frequency) and it is possible to define present chemical structures due to the interaction of the material with the infrared radiation from the spectrometer. The chemical structure determines evaluated dielectric properties of the tested material. More information about FTIR is, e.g., in the literature [18]. The determination of the chemical structure of tested materials was performed by the spectrometer Nicolet 380 (producer Thermo Scientific). The measurement was carried out in transmission mode with a resolution of $1 \mathrm{~cm}^{-1}$, when the infrared beam passes through the foil (the chemical structure is evaluated throughout the entire foil thickness).

\section{RESULTS AND DISCUSSION}

Main experimental results are the dielectric absorption analysis for the PE/HNT composites and the reference PE. This analysis is generally simple and allows not only the determination of volume resistivity but also provides a lot of information about the accumulation and release of electrical charge in tested materials. Results of standard measurement of the dielectric strength are presented. The 
chemical structure evaluation by the FTIR represents the confirmation of some conclusions of dielectric properties measurement (related mainly to the UV irradiation effect).

\subsection{Dielectric absorption analysis for different levels of filling and influence of $U V$ radiation}

The data of the current flowing through the specimen obtained during the volume resistivity measurement and modified according to the above-mentioned procedure are interpreted in the Fig. 1 for all tested materials. Displayed curves represent specifically increasing trends of $\rho_{V}\left(t_{c h}\right)$ which is calculated according to the equation (1). The Fig. 1d shows the detail of $\rho_{V}\left(t_{c h}\right)$ trends for materials only in a delivered state with an emphasis on the different rate of volume resistivity rise shortly after the voltage connection. The steady volume resistivity and polarization indexes values are summarized in the Fig. 2 for all materials before and after the exposure to UV radiation.

The first part of the dielectric absorption analysis is focused on effects of filling level on dielectric absorption. The evaluation of the effect of the filler loading is based on results ( $\rho_{V}$ and polarization index values) of measurements of specimens which were not exposed to UV radiation. Values of the $\rho_{V}$ for the PE and for the composite with $3 \%$ of the HNT are very similar and value of the volume resistivity for the composite with $7 \%$ filling level is more than double. This fact indicates that the presence of the filler (in the composite in the delivered state) causes a more complicated flowing of the conduction current through the tested specimen due to a formation of barriers in the material volume.

Polarization index values are very similar for both composites and these values are markedly higher than for the PE. Differences in polarization indexes indicate that even the minimum amount of filler particles influences the character and intensity of polarization processes. The minimum filler amount in the polyethylene volume influences even the accumulation of free charge carriers in
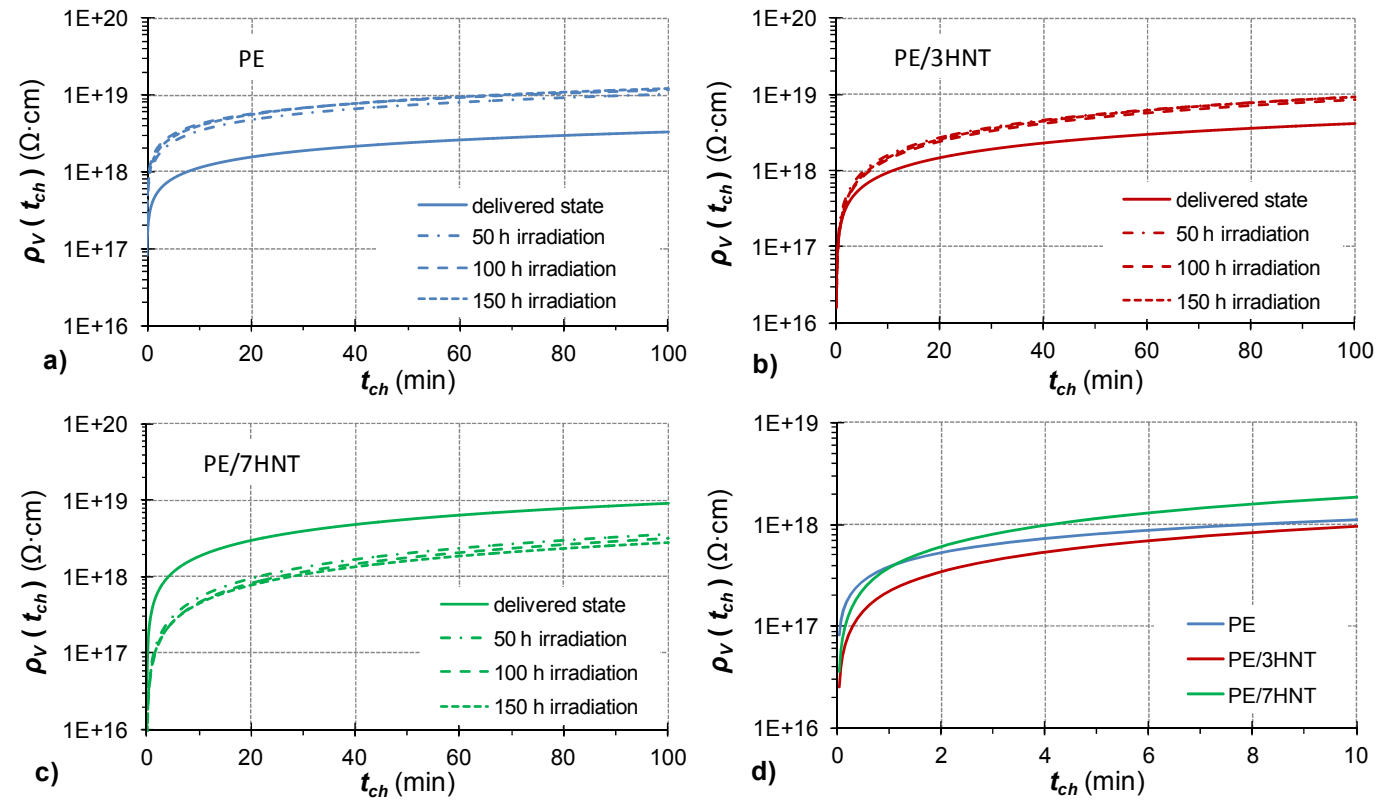

Fig. 1 Summary of time dependencies of the volume rezistivity for a) PE, b) PE/3HNT, c) PE/7HNT for the delivered state and all time periods of the exposure to UV radiation and d) detail of these dependencies for all materials in the delivered state. 

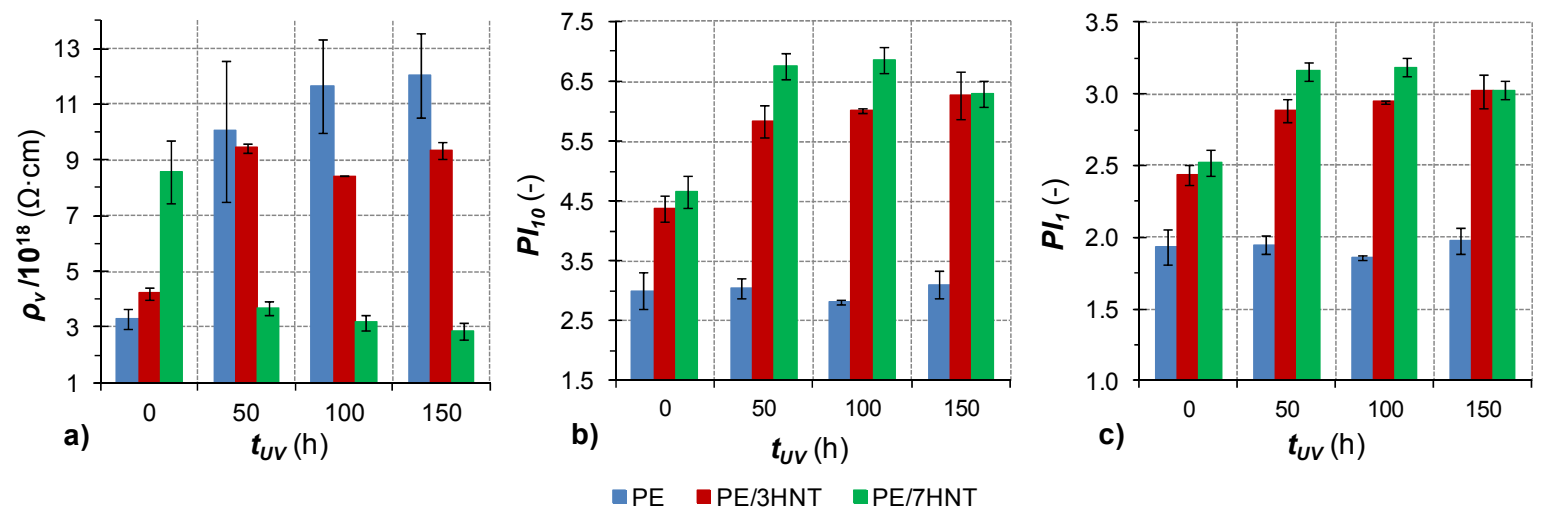

Fig. 2 Graphical comparison of a) volume resistivity, b) polarization index $P I_{I}$ and c) polarization index $P I_{10}$ (values with standard deviation ) for all materials and for the delivered state $\left(t_{U V}=0 \mathrm{~h}\right)$ and all time periods of the exposure to UV radiation.

Polarization indexes of the PE are not changed visibly due to the irradiation. The rising of polarization indexes is detected in the case of the composite with $3 \%$ of the HNT as a result of the irradiation. The composite with $7 \%$ filling level is characterized by the $P I_{1}$ and $P I_{10}$ increase after the irradiation for $50 \mathrm{~h}$ and $100 \mathrm{~h}$ and by the slight decrease of $P I_{l}$ and $P I_{I 0}$ after the irradiation for $150 \mathrm{~h}$. However, this decrease is not higher than the sum of standard deviations for UV irradiations lasting for $100 \mathrm{~h}$ and $150 \mathrm{~h}$. The increase of $P I_{1}$ and $P I_{10}$ can be explained, at least partly, by the creation of asymmetrical sections within the structure of the material as a result of the photo-oxidation. The formation of asymmetrical sections can lead to the amplification of effects of relaxation processes and to the changed trend of the absorption current as a component of the total charging current.

The evaluation of behaviour changes of the composite with $7 \%$ filling level in the case of the charging is supplemented by the characterization of this material during the discharging via regression lines of reduced resorption curves for a chosen time period of the irradiation. These regression lines are shown in the Fig. 3 and the slope decrease of lines can be interpreted generally as a deterioration of dielectric properties according to [16]. The composite discharging analysis, as well as the charging analysis, shows the most significant change between the delivered state and the irradiation lasting for $50 \mathrm{~h}$. Results of this dielectric absorption analysis are presented also in a conference paper [19].

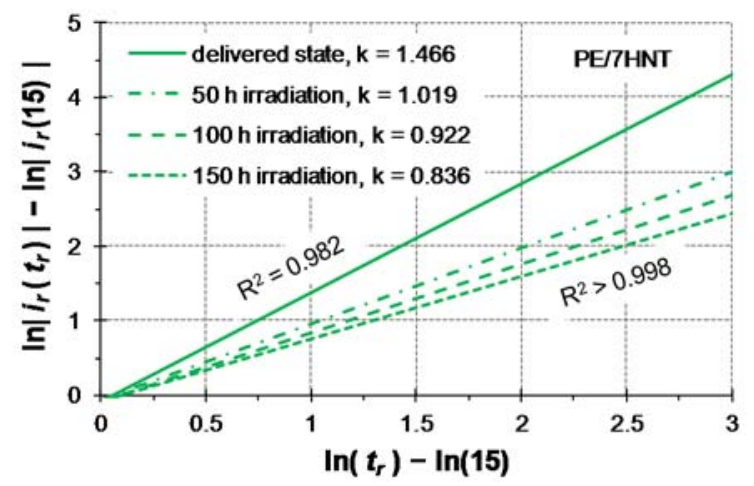

Fig. 3 Regression lines with slope $k$ and coefficients of determination for reduced resorption curves for composite $\mathrm{PE} / 7 \mathrm{HNT}$ and for all periods of the exposure to UV radiation.

\subsection{Measurement of dielectric strength}

The influence of the filling level, as well as the effect of UV radiation on the dielectric strength, is summarized in the Fig. 4. The differences of dielectric strength values for the LLDPE and composite with 3\% HNT filling between the delivered state and all UV irradiation levels are negligible (maximum difference within the range of standard deviations). However, the difference of $E_{p}$ values of composites with different filling level is significant and it is related to a large increase in a structure inhomogeneity (achieved during the extrusion) of the composite with a bigger amount of the HNT.

A large number of significant inhomogeneities, mainly air bubbles and filler agglomerates, are formed in the composite with $7 \%$ filling level. These inhomogeneities are primarily heated by the electric field and represent centres where a discharge activity originates and leads to the formation of a conductive channel through the material. Determined values of $E_{p}$ are significantly influenced by a surface roughness and structural defects of the LLDPE as results of the extrusion. This is the reason why even the values of $E_{p}$ for pure LLDPE are mentioned with a quite wide range of standard deviations. The effect of the UV irradiation compared to the influence of inhomogeneities can be considered insignificant in the case of dielectric strength measurement for tested materials. The measurement of the dielectric strength for same materials is evaluated also in a contribution [19].

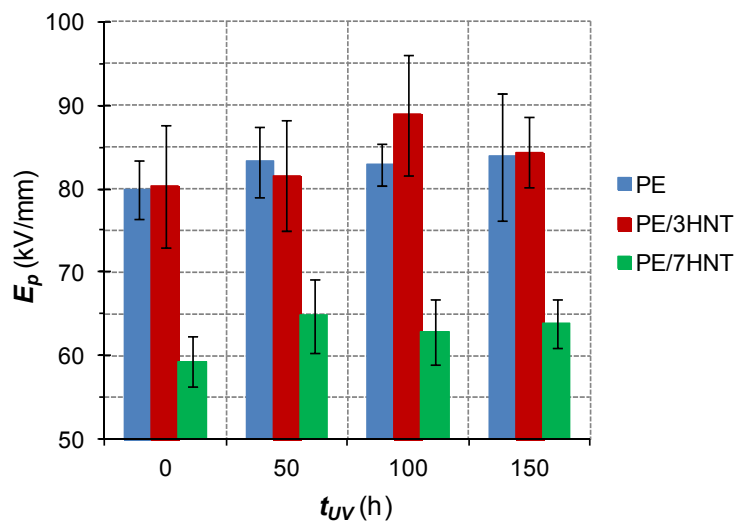

Fig. 4 Graphical summary of dielectric strength values with standard deviation for all materials and for all time periods of the exposure to UV radiation. 


\subsection{Evaluation of chemical structure changes related to UV irradiation}

The evaluation of changes in the chemical structure is based on the results of infrared spectroscopy. Overall spectra obtained by the measurement for tested materials in the delivered state are shown in the Fig. 5. The effect of the HNT addition on the basic PE spectrum is evident from these displayed spectra. A description of basic PE spectrum can be found in [8]. The presence of the HNT in materials is apparent in FTIR spectra in the region from $3500 \mathrm{~cm}^{-1}$ to $3800 \mathrm{~cm}^{-1}$ (specific $\mathrm{O}-\mathrm{H}$ bonds) and in the region from 500 $\mathrm{cm}^{-1}$ to $1200 \mathrm{~cm}^{-1}$, where spectral bands relating to $\mathrm{Al}-\mathrm{O}$, $\mathrm{Si}-\mathrm{O}$ and also $\mathrm{O}-\mathrm{H}$ bonds forming the HNT structure. The spectrum and detailed assignment of spectral bands (wavenumbers for peak absorbances) to chemical bonds is in the literature [20]. The presented evaluation of the influence of UV radiation is realised with a focus on a limited wavenumbers interval, where the most significant changes after the irradiation can be detected against the spectra of materials in the delivered state. The sufficient detailed view of FTIR spectra for all materials and all time periods of exposure to UV radiation is shown in the Fig. 6.

The displayed wavenumbers interval (Fig. 6) is related to the region in which overlapping spectral bands of molecular vibrations of chemical bonds in carbonyl groups (based on $\mathrm{C}=\mathrm{O}$ bond) are occurred commonly. These chemical groups can be specified, e.g., as aldehyde carbonyl, ketonic carbonyl or carboxylic groups [8, 21]. The formation of carbonyl groups is accompanied by another radical reactions leading to the separation of simpler chemical structures form the long branched chain of a polymer and by the formation of final degradation products (aldehydes, ketones, carboxylic acids, esters and $\gamma$-lactones) as reported in $[6,11,21]$.

Detailed spectra in the Fig. 6 indicate an increase in the occurrence of carbonyl groups due to the irradiation. The increase in the absorbance of spectral bands assigned to carbonyl groups (representing the concentration of mentioned bonds in the material) is approximately linear with the irradiation time increase. The most considerable is the increase in the intensity of the spectral band with a central wavenumber of $1715 \mathrm{~cm}^{-1}$, which is related to the carbonyl group located between a pair of methylene groups [8]. The measurement by FTIR confirms that the clay filler addition into the polyethylene significantly accelerates the formation of photo-degradation products compared to the pure PE, as already mentioned in the evaluation of the dielectric absorption analysis. However, the trend of linear increase in the carbonyl groups concentration does not correspond to the non-linear trend of changes in measured dielectric parameters. This is evidence that the dielectric properties do not influenced only by the formation of mentioned degradation products, but also by other structural changes of materials that are not easily recognizable by the used FTIR technique. These other structural changes are mainly the partial crosslinking and the fragmentation of slightly branched PE structure. These structural changes of the PE are most likely influenced also by the presence of halloysite nanotubes and are manifested mainly in the first time period of the exposure to UV radiation (within $50 \mathrm{~h}$ of the irradiation).

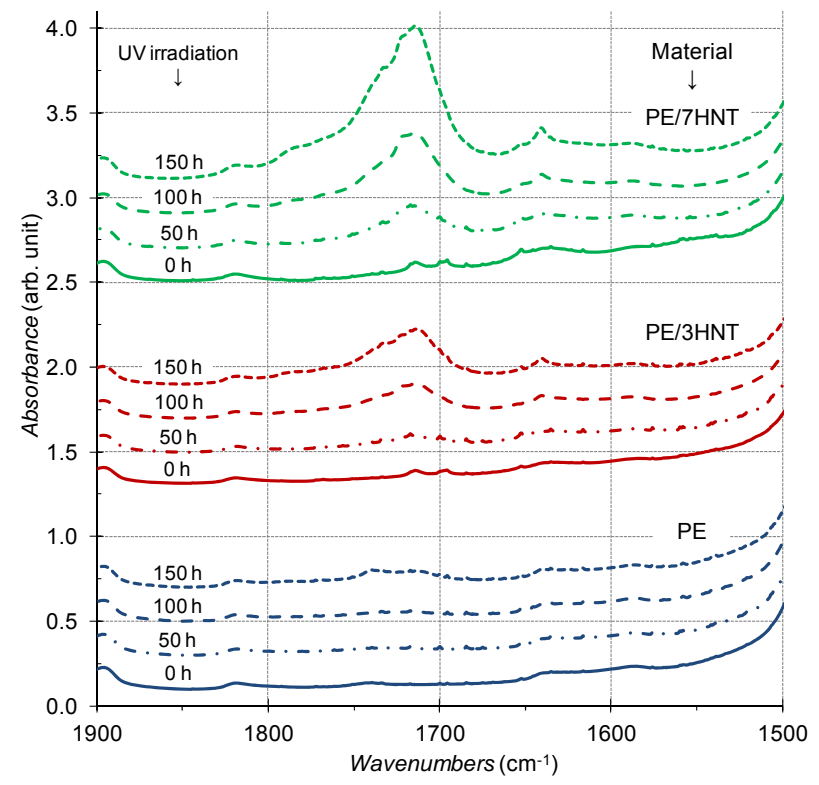

Fig. 6 Detailed view of the region of FTIR spectra of all tested materials with visible effects of UV radiation.

\section{CONCLUSIONS}

The evaluation of the comprehensive dielectric absorption analysis and the measurement of the dielectric strength prove different dielectric properties of the composites PE/HNT compared to the pure PE. It was found out that the level of influence on dielectric properties is strongly dependent on the amount of filler. The filler loading affects different evaluated parameters differently. The

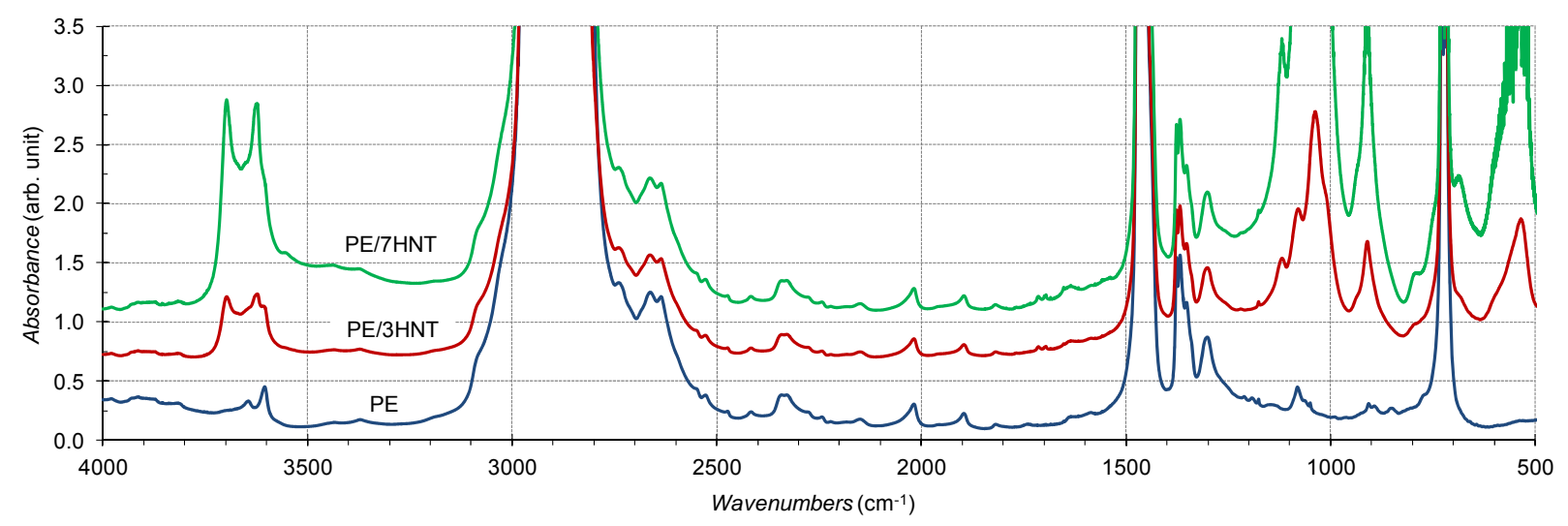

Fig. 5 FTIR spectra of polyethylene and both tested composites with visible influence of an addition of HNT on the spectrum of base polyethylene. 
volume resistivity and the dielectric strength are not markedly changed but values of polarization indexes visibly increased in the case of the composite with 3\% filling level compared to the PE. The composite with $7 \%$ of the HNT is characterized not only by the evident increase in $P I_{l}$ and $P I_{10}$, but also by the evident decrease in the volume resistivity and dielectric strength compared to the PE. The increasing amount of filler particles is connected with a higher probability of the occurrence of undesirable inhomogeneities (filler agglomerates and air bubbles) in the composite structure.

The UV radiation influence is significantly dependent on the filler amount in the composite. The composite with $3 \%$ of the HNT exhibits after the irradiation lasting for $50 \mathrm{~h}$ the similar increase in the volume resistivity as the PE. On the contrary, the composite with $7 \%$ filling level exhibits the significant reduction in the volume resistivity after the UV irradiation lasting for $50 \mathrm{~h}$. Changes in other selected dielectric parameters are not important in the case of all tested materials.

Structural analyses performed by FTIR demonstrate visible changes in the chemical structure of tested materials associated with the formation of standard photo-oxidation products (with an occurrence of carbonyl groups) due to irradiation. However, the trend of increase in the carbonyl groups concentration does not correspond to assumptions related mainly to the trend of the volume resistivity change. An exhaustive explanation of the effect of UV radiation can be possible only after a more detailed examination of other material structure changes which are not supported by measurement (e.g., the PE crosslinking) non-substantiated. The assessment of these changes can be the subject of a follow-up research.

\section{ACKNOWLEDGMENTS}

This research was supported by the Ministry of Education, Youth and Sports of the Czech Republic under the RICE - New Technologies and Concepts for Smart Industrial Systems, project No. LO1607, by the Technology Agency of the Czech Republic, project No. TE01020455, by the Student Grant Agency of the University of West Bohemia, project No. SGS-2018-016 "Diagnostics and Materials in Electrical Engineering".

\section{REFERENCES}

[1] HARPER, Ch. A.: Handbook of Plastics, Elastomers, and Composites, 4th ed. New York: McGraw-Hill, 2002. ISBN 9780071384766.

[2] LAOUTID, F. - BONNAUD, L. - ALEXANDRE, M. - LOPEZ-CUESTA, J. M. - DUBOIS, Ph.: New prospects in flame retardant polymer materials: From fundamentals to nanocomposites, Materials Science and Engineering: Reports, No. 63, pp. 100-125, 2009. DOI 10.1016/j.mser.2008.09.002.

[3] SZPILSKA, K. - CZAJA, K. - KUDLA, S.: Thermal stability and flammability of polyolefin/halloysite nanotubes composites, Polimery, No. 60, pp. 672-679, 2015. DOI 10.14314/polimery.2015.673.
[4] JINMEI, Z. - JUNGUO, G. - JIAYIN, L. QUANQUAN, J. - MINGYAN, Z. - XIAOHONG, Z.: Studies on Electrical Tree and Partial Discharge Properties of PE/MMT Nanocomposites, Proceedings of 2008 International Symposium on Electrical Insulating Materials, pp. 311-314, 2008. DOI 10.1109/ISEIM.2008.4664560.

[5] GOUDA, O. E. - MAHMOUD, S. F. - EL-GENDY, A. A. - HAIBA, A. S.: Improving the Dielectric Properties of High Density Polyethylene by Incorporating Clay-Nanfiller, World Journal of Engineering and Technology, no. 2, pp. 289-297, 2014. DOI 10.4236/wjet.2014.24030.

[6] QIN, H. - ZHAO, Ch. - ZHANG, S. - CHEN, G. YANG, M.: Photo-oxidative degradation of polyethylene/montmorillonite nanocomposite, Polymer Degradation and Stability, no. 81, pp. 497-500, 2003. DOI 10.1016/ S01413910(03)00136-8.

[7] KITSINELIS, S.: Light Sources: Basics of Lighting Technologies and Applications. Boca Raton: CRC Press, 2015. ISBN 978-1-4822-4369-7.

[8] DOLEŽEL, B.: Odolnost plastů a pryži <in Czech>. Prague: SNTL, 710 p., 1981.

[9] ZWEIFEL, H.: Stabilization of Polymeric Materials. Berlin: Springer-Verlag, 1998. ISBN 978-3-64280307-9.

[10] RABEK, J. F.: Photodegradation of Polymers Physical Characteristics and Applications. Berlin: Springer, 1996. ISBN 978-3-642-80090-0.

[11] SALVALAGGIO, M. - BAGATIN, R. FORNAROLI, M. - FANUTTI, S. - PALMERY, S. - BATTISTEL, E.: Multi-component analysis of lowdensity polyethylene oxidative degradation, Polymer Degradation and Stability, No. 91, pp. 2775-2785, 2006. DOI 10.1016/j.polymdegradstab.2 006.03 .024

[12] LOMAKIN, S. - NOVOKSHONOVA, L. BREVNOV, P. - SHCHEGOLIKHIN, A.: Thermal properties of polyethylene/montmorillonite nanocomposites prepared by intercalative polymerization, Journal of Materials Science, vol. 43, no. 4, pp. 1340-1353, 2008. DOI 10.1007/s10853007-2295-1.

[13] ANNABI-BERGAYA, F. - THENG, B. K. G. LAGALY, G.: Handbook of Clay Science. Amsterdam: Elsevier, 1248 p., 2006. ISBN 978-0-08044183-2.

[14] IEC 62631-3-1, Dielectric and resistive properties of solid insulating materials - Determination of resistive properties (DC methods), 2016.

[15] IEEE Std 43-2000 (R2006), IEEE recommended practice for testing insulation resistance of rotating machinery, approved 2000 and reaffirmed 2006. 
[16] MENTLÍK, V.: Dielektrické prvky a systémy <in Czech>, 1st ed. Prague: BEN - technical literature, 2006. ISBN 80-7300-189-6.

[17] IEC 60243-1, Electrical strength of insulating materials - Test methods - Tests at power frequencies, 1998.

[18] SMITH, B. C.: Fundamentals of Fourier transform infrared spectroscopy. Boca Raton: CRC Press, 2011. ISBN 978-1-4200-6930-3.

[19] KADLEC, P. - POLANSKÝ, R.: Dielectric Absorption Analysis and Dielectric Strength of LLDPE/HNT Composites Exposed to UV Radiation, Proceedings of the 7th International Scientific Conference. Bratislava: STU in Bratislava, pp. 1-6, 2018. ISBN 978-80-89983-03-2.

[20] YUAN, P. - THILL, A. - BERGAYA, F.: Nanosized Tubular Clay Minerals: Halloysite and Imogolite, 2nd ed. Amsterdam: Elsevier, 2016. ISBN 978-0-08100293-3.

[21] RABEK, J.: Polymer Photodegradation Mechanisms and experimental methods. Dordrecht: Springer, 1995. ISBN 978-94-010-4556-8.

Received September 13, 2018, accepted October 23, 2018

\section{BIOGRAPHIES}

Petr Kadlec was born in 1990 in Pilsen (Czech Republic). In 2014 he graduated with Master's degree (Ing.) with distinction in study programme Commercial electrical engineering at the Faculty of Electrical Engineering at the University of West Bohemia in Pilsen. He started $\mathrm{PhD}$ study in 2014 in the field of research and development of materials for electrical insulation systems. Currently he is completing thesis with the title "Electrical insulating composite materials with reduced flammability“. He is a main author or co-author of about thirty contributions to conferences and journals since beginning of $\mathrm{PhD}$ study. His research is focused primarily on polymer composites with perspective filler called halloysite nanotubes.

Radek Polanský was born in 1978 in Pilsen (Czech Republic). He received his Ph.D. degree from the University of West Bohemia, Pilsen, Czech Republic in 2005. He has been working as an Associate Professor at the same university since 2008 and as a Senior Researcher at Regional Innovation Centre for Electrical Engineering (since 2012). His research interests include the diagnostics and development of new materials and systems for electrical engineering, application of structural analyses in electrical technology diagnostics and study of aging process of engineering polymers. Radek Polanský is a Senior Member of IEEE since 2012 (IEEE Member within the years 2006-2012). 